\title{
ACPE: A computerized system for running small-group decision-making experiments
}

\author{
WILLIAM P. BOTTOM, CHERYL L. EAVEY, and GARY J. MILLER \\ Washington University, St. Louis, Missouri \\ and \\ STEPHEN FOSTER \\ Heuristic Technologies, St. Louis, Missouri
}

\begin{abstract}
Small groups are called upon to make important policy decisions under a wide variety of procedural constraints. ACPE is a flexible, computerized system for conducting small-group voting experiments. It permits researchers to examine the impact of electronic communication on group deliberation and choice. The system runs under a variety of different personal computer networks and is designed to permit the specification of voting rules, communication, and group sizes. The system also facilitates the study of group process by tracking all messages sent and votes taken. An experiment in which the system was used is briefly described.
\end{abstract}

In business and politics, important decisions are often made by groups. A corporate board may decide the fate of an executive team. A congressional committee may decide the fate of a public program. The nature of these groups and the rules within which they operate vary tremendously. Although some decisions are made by consensus, others involve some formal voting procedure such as majority rule or super-majority rule.

Theorists have devised a number of models that are purported to predict the choices of groups under various institutional constraints. Sometimes we can test the competing predictions of these models with field data, such as the voting records of legislators. However, many of these models, especially those from the gametheoretic literature, require specific data on preferences; such data can be difficult, if not impossible, to gather in the field. The laboratory setting provides a useful substitute for the field in the absence of the necessary field data and serves as an appropriate complement to the field when field data are more readily available (Smith, 1976).

In the past, laboratory experiments on group decision making have been conducted almost exclusively in settings with face-to-face interactions. However, given the rapid advances in computing and communication capabilities, groups are increasingly able to render decisions

Support for this research was provided by National Science Foundation Grant SES 9210114 and by a grant from the Center for Business, Law, and Economics at the John M. Olin School of Business. The authors wish to thank the editor, Patrick Laughlin, and three anonymous reviewers for their helpful suggestions. W.P.B., C.L.E., and G.J.M. are affiliated with the John M. Olin School of Business. Correspondence should be addressed to W. P. Bottom, Washington University, Campus Box 1133, One Brookings Drive, St. Louis, MO 63130 (e-mail: bottomb@simon.wustl.edu). by electronic mail without face-to-face interactions. Some corporations that have switched to computerized meetings believe that computer-mediated discussions are more productive than face-to-face meetings (Bulkeley, 1992), and at least one study suggests that computers result in more efficient negotiations between unions and management (Herniter, Carmel, \& Nunamaker, 1993). Researchers are only beginning to understand the procedural and/or substantive effects of these changes on group decision making (e.g., Kiesler \& Sproull, 1992). In order to assess the effect of computer-mediated discussions on group decisions, we must develop tools that allow us to run experiments under a variety of institutional constraints.

ACPE (for automation of committee process experiments) is a computer-driven system for conducting small-group decision-making experiments. Although it is tailored for situations in which individual member preferences are modeled in a one- or two-dimensional issue space, the program can also be used for a wide range of other contexts such as mock juries (Bray \& Kerr, 1982), intellective group tasks (Laughlin, 1980), or ultimatum bargaining (Ochs \& Roth, 1989). The system is flexible in several respects. It operates under a variety of computer environments and permits specification of the institutional features of the decision-making problem. It allows for explicit control over the degree of communication between subjects, and the results from computermediated experimental groups may be compared with those obtained from face-to-face deliberations under similar institutional constraints. For teachers of political science, social psychology, or management interested in teaching their students about voting cycles, agenda control, or coalition formation, ACPE should provide a convenient means for running interactive classroom exercises that teach these concepts experientially. 


\section{Hardware Requirements}

The program can be run on any NET BIOS-compatible network linking IBM PC or compatible microcomputers. The individual computers must have at least $460 \mathrm{~K}$ RAM running DOS Version 5.0 or later. They also require a VGA monitor and mouse. The computer operated by the experimenter must have, in addition, a hard disk with at least $5 \mathrm{MB}$ of free space.

\section{Running ACPE}

Before ACPE is used to conduct an experiment, a number of operational decisions must be made to define the institutional features of the voting procedure. The experimenter specifies these features by selecting options from a menu of choices. These decisions can be saved for future experiments as a configuration file.

In defining a configuration, the experimenter specifies the size of the group, the time limit for casting a vote, agenda control (who has the power to put a proposal to a vote), the status quo outcome, the number of votes needed to pass a proposal, the treatment of abstentions, and how the meeting will be adjourned. Please note that while ACPE controls a number of features of the experimental setting, the software does not currently permit the specification of committee preferences. In order to induce preferences in subjects, payoff schedules must be provided separately. Figure 1 provides an example of such a payoff schedule for one player. This player has an ideal point at $x=39, y=68$. In this example, the ideal point provides a payoff of $\$ 9.45$ for the subject.

Once the configuration has been determined, the experimenter activates each of the committee members' computers and starts the meeting. The subjects make decisions by typing in messages and pointing the cursor at various boxes on the screen. A clock informs subjects of the amount of time that remains for casting votes on proposals on the floor. At any time, the experimenter can communicate with and instruct committee members by typing and sending messages. All parties have a scrolling message log that contains all messages sent throughout the experiment; these are identified by the prefix of the sender. This prefix will be either $\mathrm{C}$ for the chairperson or a number (from 1 to $n$ ) that serves as a means of player identification. The experimenter can also terminate the meeting at any time with a keystroke.

A complete record of the meeting is maintained in a file entitled ACPE.RES. The file contains a timed, chrono-

PLAYER 1

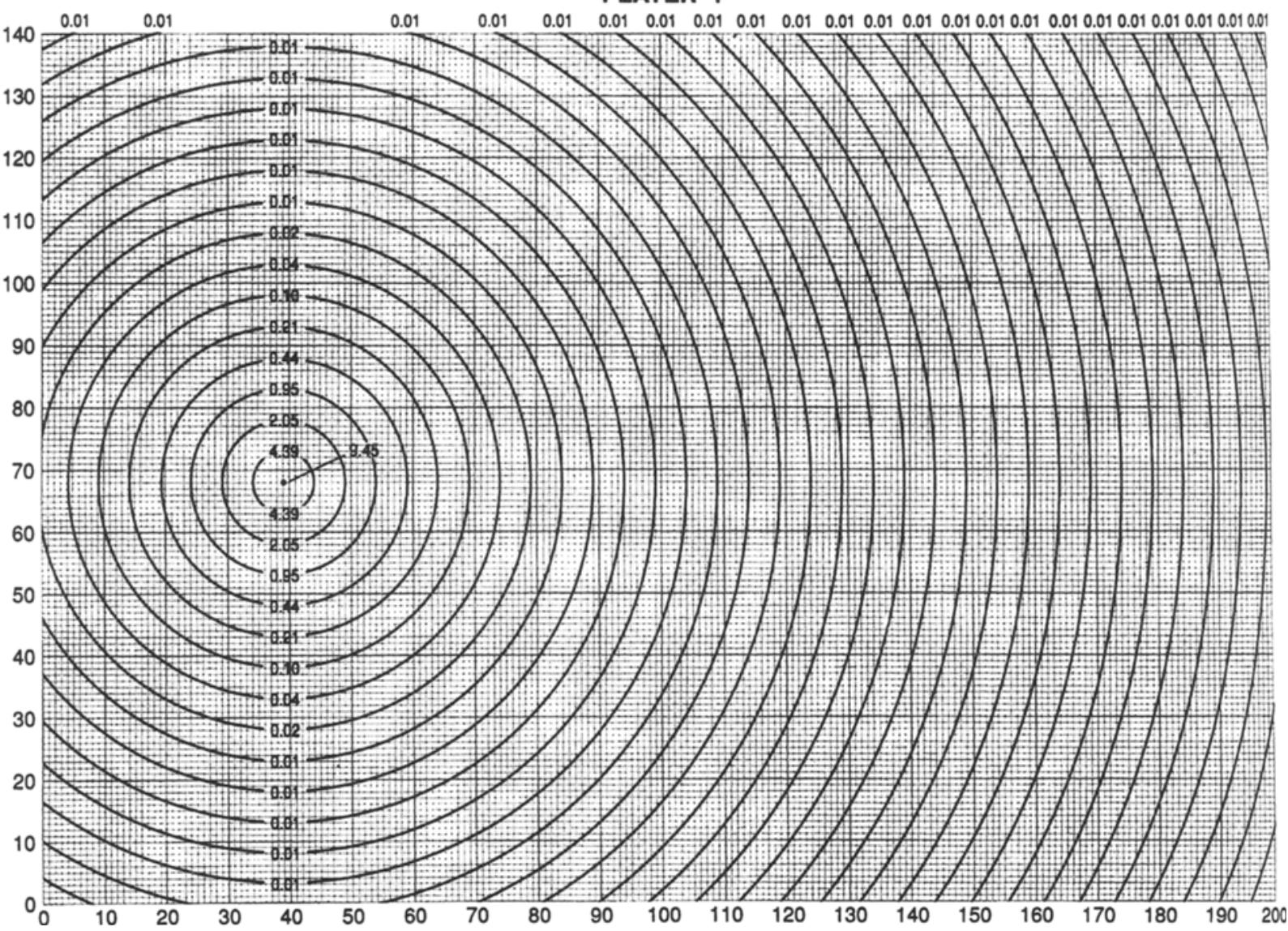

Figure 1. A sample payoff schedule for one player in a majority rule game involving a two-dimensional policy space. 
logical record of all events occurring during a meeting. The record includes messages sent by the chair or committee members along with proposals made, votes cast, and the outcome of every vote. It also provides a summary count of the frequency of events in a session. Such record keeping should facilitate the analysis of the process of committee decision making.

\section{The User Interface}

ACPE is menu driven and simple to learn. The mouse is used to activate choices for both the experimenter and the committee members. Each member's screen is divided vertically into two halves. The right half contains the message log of all communications sent during the session, indexed by the sending party. This log can be scrolled by pointing the mouse at up or down arrows beside the $\log$, or by holding and dragging on a button in the desired direction.

The lower right half of the screen is the communication box. Subjects can compose a message of any length in this box. The cursor is placed in the box by pointing the mouse. The message can be edited before sending; lengthy messages can be scrolled in a manner similar to that for the message log.

The upper left portion of the screen contains all decision-making functions. Initially subjects may type in the $x$ and $y$ coordinates of their preferred alternative. Using the mouse, they can press PROPOSE, a box that sends the proposals to the committee for consideration. Alternatively, they can press ADJOURN, a box that sends a proposal for adjournment and acceptance of the status quo to all committee members for consideration. In the event that multiple subjects desire to make a proposal, the system will automatically select from among them the first to be sent. Subjects who are not granted agenda control do not have these action options on their screen, so they may only suggest proposals through the message box.

Once a proposal is on the floor for consideration, the screen changes from PROPOSE-ADJOURN mode to ACCEPTREJECT mode. By using the mouse, subjects can cast votes for or against the proposed alternative. The screen displays a tally of the distribution of votes (yea, nay, or abstentions) and a listing of the committee members who supported or opposed the proposed alternative. Once votes are cast or time expires without an acceptance, the screen returns to the PROPOSE-ADJOURN mode.

\section{A Study Using ACPE}

We tested ACPE with a design used frequently in the face-to-face setting: a five-person game containing a core, or set of undominated alternatives. Consider the ordinal preferences displayed in Figure 2 . The core of this game is the point $(39,68)$, which coincides with the ideal point of Player 1. When Fiorina and Plott (1978) examined this design in a face-to-face setting with full communication (i.e., players could discuss anything but the cardinal payoffs associated with an alternative) under parliamentary rules of order, they found that outcomes clustered on or around the core. Hoffman and Plott (1983) later replicated their results under an open agenda rule. They too found that outcomes clustered around the core alternative.

Using the open agenda rule of Hoffman and Plott (1983), the cardinal preferences given in Fiorina and Plott (1978; see also Eavey, 1993), and the design given in Figure 2, we ran 10 face-to-face experiments and 9 ACPE computer-mediated experiments to determine whether the computer-mediated experiments would generate results comparable to those from the face-to-face setting.

The subjects for these experiments were primarily undergraduate students enrolled in a course on business and public policy who participated on a voluntary basis in order to earn money and to receive extra credit for the course. The subjects were randomly assigned to either the ACPE procedure or the face-to-face procedure. The students had received introductory exposure to the concepts of voting paradoxes and Condorcet equilibrium (see Ordeshook, 1986) but had not discussed spatial models of voting or the concept of a core. Following the experiment, each subject was paid according to the committee vote and the payoff chart.

The specifics of the computer mediated games were as follows: ACPE procedures were designed to match those employed by Hoffman and Plott (1983) in the faceto-face setting. The subjects were allowed to make an unlimited number of formal and informal proposals, but once a proposal was accepted by a majority of the committee, the meeting was terminated and the subjects were paid on the basis of the committee choice. Thus, our configuration specified five players, each of whom were given agenda control, a 90-sec time limit for voting, and a status quo point of $(200,140)$. Three votes were required for the passage of a proposal, and three votes were required for adjournment.

Prior to interacting with the computer, the subjects were given some very general information about spatial committee games. They were instructed that during the game, they could not convey any information about the cardinal (monetary) value of their payoffs (e.g., "that offer is worth $\$ 3.00$ to me"), but they were free to provide ordinal expressions of preference (e.g., "I prefer a higher $x$ value").

Then they were given extensive instructions on the use of ACPE. The subjects were informed that all communication with other players would be conducted entirely via networked computers. The subjects practiced sending messages and proposals without yet having any knowledge of their specific payoffs for the experiment. After ensuring that all subjects were comfortable with the use of the computer, the experimenter detailed the rules of an open agenda game. After completion of the instructions, each subject was provided with a two-dimensional grid, as in Figure 1, depicting the ideal points and the concentric circular indifference curves that 


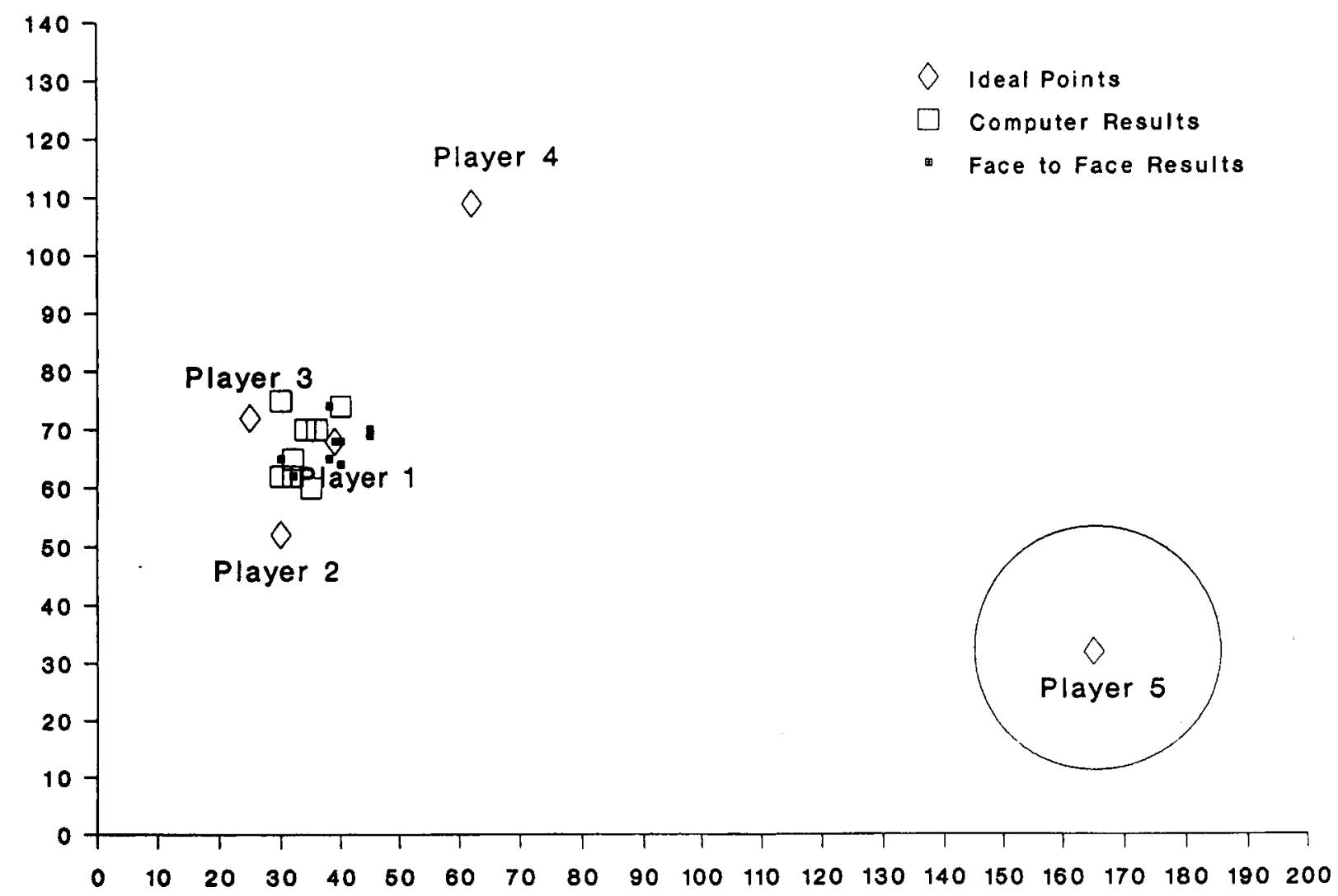

Figure 2. Fiorina-Plott design of comparative results for face-to-face and ACPE sessions.

would determine the dollar payoffs for all points on the grid. Finally, the subjects were required to complete a short quiz to verify their understanding of the payoffs.

The outcomes are also plotted in Figure 2, with different marks for computer and face-to-face conditions. As one can see, there was some variability in settlement patterns, but most cluster around the core. A MannWhitney test for the difference in median Euclidean distance indicates that computer-mediated outcomes were not significantly different $(p=.23)$ from face-to-face outcomes. Moreover, these outcomes are comparable to those generated by Hoffman and Plott (1983) in their face-to-face experiments. A Mann-Whitney test for the difference in median Euclidean distance indicates that there is no difference between our combined results and those reported in Hoffman and Plott $(p=.125)$. Thus, the system seems to provide sufficiently free communication to permit experimental groups to find solutions as they would under face-to-face deliberations. Table 1 provides part of the exchange from one ACPE session. This kind of information could be used to test processbased hypotheses about group deliberation.

Of course, under some circumstances, the computer and face-to-face environments could produce different outcomes. For example, in our experiments, the only alternative that offered everyone at least $\$ 5.00$ was the core; thus, the core of this game was also the cardinally most fair alternative. In face-to-face experiments in which the core does not coincide with the cardinally fair alternative, cardinally fair alternatives are frequently chosen over game-theoretic solutions like the core (see Eavey, in press). If, as we believe, fairness is a product of social norms, and if, as Kiesler and Sproull (1992) suggest, social context cues are diminished by electronic mail, we would conjecture that the frequency of fair outcomes would decrease in computer-mediated environments.

\section{Other Applications}

Although ACPE is ideally suited to the study of committee voting problems, it can also be set up for examining other situations. With the game set to two players and with the agenda control limited to only one of these, the game can be set up to examine ultimatum bargaining (Ochs \& Roth, 1989). The parameters should also be set to adjourn on either a yea or nay vote. In an ultimatum problem, $x$ would stand for the amount of the pie that the divider would receive and $y$ would stand for the amount that the acceptor would get. A nay vote would then be equivalent to rejecting the offer.

A reviewer also suggested an implementation for mock jury research. If jurors are instructed to set $x=0$ and $y=0$ to express a guilty verdict and $x=1, y=1$ to express a not guilty verdict, the system can provide a 
Table 1

An Excerpt From the ACPE Results File of One Group Decision-Making Session

\begin{tabular}{|c|c|c|}
\hline & & 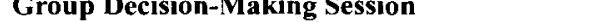 \\
\hline \# & Time & Description of Event \\
\hline 2 & $4: 37$ & $\begin{array}{l}\text { Discussion entered by } 2 \text {. } \\
\text { Yes, but look at the three points nearest to } \\
\text { one another }\end{array}$ \\
\hline 4 & $5: 01$ & $\begin{array}{l}\text { Discussion entered by } 4 \text {. } \\
30,66 \text { sucks for me. How about } 43,77\end{array}$ \\
\hline 5 & $5: 32$ & $\begin{array}{l}\text { Discussion entered by } 5 \text {. } \\
\text { I need } \mathrm{x} \text { to be closer to } 100, \text { at least, please? }\end{array}$ \\
\hline 3 & $6: 01$ & $\begin{array}{l}\text { Discussion entered by } 3 \text {. } \\
\text { Well, if we're all cooperating as mentioned before, } \\
\text { let's find an approximate best point }\end{array}$ \\
\hline 2 & $6: 12$ & $\begin{array}{l}\text { Discussion entered by } 2 \text {. } \\
\quad \text { A good average seems to be } 30,66-67\end{array}$ \\
\hline 1 & $6: 35$ & $\begin{array}{l}\text { Discussion entered by } 1 \text {. } \\
\text { Yeah, we are sharing the earnings }\end{array}$ \\
\hline 2 & $6: 46$ & $\begin{array}{l}\text { Discussion entered by } 2 \text {. } \\
\text { It looks good for all of us }\end{array}$ \\
\hline 1 & $6: 59$ & $\begin{array}{l}\text { Discussion entered by } 1 \\
\text { Anyone disagree ?? }\end{array}$ \\
\hline 5 & $7: 02$ & $\begin{array}{l}\text { Discussion entered by } 5 \text {. } \\
\text { If you propose that then there is nothing for } \\
\text { me to share!!! }\end{array}$ \\
\hline 4 & $7: 15$ & $\begin{array}{l}\text { Discussion entered by } 4 \text {. } \\
\text { What's this about sharing earnings?+ }\end{array}$ \\
\hline 1 & $7: 19$ & $\begin{array}{l}\text { Discussion entered by } 1 \text {. } \\
\text { Look } 5 \text {, you will get a share too }\end{array}$ \\
\hline 2 & $7: 24$ & Proposal $30(\mathrm{X}), 30(\mathrm{Y})$ made by 2 \\
\hline 5 & $7: 31$ & Member voted Nay. \\
\hline 2 & $7: 35$ & Member voted Yea. \\
\hline
\end{tabular}

very useful electronic communication system for studying group deliberation patterns.

\section{Availability}

The system may be obtained from the authors; the package will include a disk containing the compiled programs to install ACPE along with a manual describing its features and applications in more detail. The purchaser should specify a format for the manual. It may be obtained as either a Microsoft Word or WordPerfect for Windows document or in hard copy form. The cost of the package is $\$ 12.00$ to cover postage and copying. Correspondence should be addressed to: W. P. Bottom, Washington University, Campus Box 1133, St. Louis, MO 63130 (e-mail: bottomb@simon.wustl.edu).

\section{REFERENCES}

BraY, R. M., \& KERR, N. L. (1982). Methodological considerations in the study of the psychology of the courtroom. In N. Kerr \& R. Bray (Eds.), The psychology of the courtroom (pp. 287-323). Orlando, FL: Academic Press.

BULKELEY, W. M. (1992, January 28), "Computerizing" dull meetings is touted as an antidote to the mouth that bored. Wall Street Journal, pp. B1-B2.

EAvEY, C. L. (1993). The selection set and committee games: A comment on Salant and Goodstein. Unpublished manuscript, Washington University, John M. Olin School of Business.

EAvEY, C. L. (in press). Preference-based stability: Experiments on cooperative solutions to majority rule games. In N. Schofield (Ed.), Social choice and political economy. Dordrecht, The Netherlands: Kluwer.

Fiorina, M., \& Plott, C. (1978). Committee decisions under majority rule: An experimental study. American Political Science Review, 72, 575-598.

Herniter, B. C., Carmel, E., \& Nunamaker, J. F., Jr. (1993, April). Computers improve efficiency of the negotiation process. Personnel Journal, pp. 93-99.

Hoffman, E., \& Plott, C. (1983). Pre-meeting discussions and the possibility of coalition breaking procedures in majority rule committees. Public Choice, 40, 21-39.

KIESLER, S., \& Sproull, L. (1992). Group decision making and communication technology. Organizational Behavior \& Human Decision Processes, 52, 96-123.

LAUGHLIN, P. R. (1980). Social combination processes of cooperative problem-solving groups on verbal intellective tasks. In M. Fishbein (Ed.), Progress in social psychology (Vol. 1, pp. 127-155). Hillsdale, NJ: Erlbaum.

Ochs, J., \& Roth, A. E. (1989). An experimental study of sequential bargaining. American Economic Review, 79, 355-384.

ORDESHOOK, P. C. (1986). Game theory and political behavior. Cambridge: Cambridge University Press.

SмIтн, V. L. (1976). Experimental economics: Induced value theory. American Economic Review, 66, 274-279.

\section{NOTE}

1. Two experiments, one from the computer-mediated sessions and one from the face-to-face sessions, were omitted from the analysis. In the one face-to-face experiment, we discovered from our debriefing that one player had misunderstood the instructions and had voted for a proposal under the mistaken belief that other alternatives could then be proposed and voted on in its place.

The computer-mediated experiments presented a different kind of problem. The layout of our computer screen, combined with the speed at which players could propose alternatives for consideration, resulted in players voting "yea" for an alternative when they believed they were proposing a different alternative. We have corrected the layout of the screen so that this is not a problem, and we have omitted the one outcome from our analysis which resulted from the computer glitch.

(Manuscript received August 20, 1993; revision accepted for publication June 21, 1994.) 